\title{
Green IT: A Study and Analysis of Environmental Impact of Social Networks and Search Engines
}

\author{
S.Pandikumar \\ Department of Computer Science, \\ Thiagarajar College, India,
}

\author{
S.P.Kabilan \\ Department of Computer Science, \\ Madurai Kamaraj University \\ College, India.
}

\author{
L. Amalraj \\ Department of Physics, \\ V.H.N.S.N College, India.
}

\begin{abstract}
Green IT is a hot topic today and will continue to be an important issue for several years to come and Social Networks and Search Engines too. The use of IT has exploded in several areas, improving human lives and work and offering convenience along with several other benefits. Today in particularly the social networks and search engines are the seventh sense of IT users and professionals. Users are passionate about advances in and widespread adoption of social networks. However, SN (Social Networks) and SE (Search Engines) has been contributing to environmental problems, which most people don't realize. SN and SE servers need huge amount of data centers and other IT infrastructure. It consumes significant amounts of electricity, placing a heavy burden on electric grids and contributing to greenhouse gas emissions. Additionally, IT infrastructure hardware poses severe environmental problems both during its production and its disposal. Greener Social Network and Green Search Engines benefits the environment by improving energy efficiency, lowering greenhouse gas emissions, using less harmful materials, and encouraging effective use of social networks and search engines. This paper brings out the secret of power consumption and environmental impact of social networking and search engines and it proposes methodology to greener IT.
\end{abstract}

Keywords: Green IT, Green Computing, Social Networks, Search Engines, Green Internet, CO2 Emission, Environmental Impact

\section{INTRODUCTION}

Modern technologies are giving us lots of creditability and feasibility. Newton's Third Law of Motion states that "For every action, there is an equal and opposite reaction.", therefore consumption of energy sources has a negative reaction on the environment. Today computers and internet have become a necessity not only in business but also human lives. No doubt, internet has made doing various tasks very easy and efficient; they pose a great problem which is affecting the environment adversely. As the number of internet users is increasing day by day, in 2012, 2.1 billion internet users are worldwide and 45\% share of internet users are under the age of 25 . Even 3.146 billion of email accounts in worldwide. So the amount of electricity consumed by them which in turn is increasing the carbon content in atmosphere. According to research the overall internet users release around 300 million tonnes of $\mathrm{CO} 2$ a year [1].

In specific every internet actions get data from server and the data are crossed through so many networking devices like routers, WAN switches, LAN switches, Hubs. These devices required significant amount of power to operate. Table 1 reveals network devices required $14.05 \mathrm{TW} / \mathrm{hr}$ for one year [2].

Table 1. Network device power consumption

\begin{tabular}{|c|c|c|}
\hline Devices & $\begin{array}{c}\text { Approximate } \\
\text { Deployed }\end{array}$ & $\begin{array}{c}\text { Total Annual } \\
\text { Power } \\
\text { Consumption }\end{array}$ \\
\hline Hubs & 200.5 million & $3.6 \mathrm{TW} / \mathrm{hr}$ \\
\hline $\begin{array}{c}\text { LAN } \\
\text { Switches }\end{array}$ & $2,01,000$ & $4.2 \mathrm{TW} / \mathrm{hr}$ \\
\hline $\begin{array}{c}\text { WAN } \\
\text { Switches }\end{array}$ & $1,10,000$ & $1.15 \mathrm{TW} / \mathrm{hr}$ \\
\hline Routers & 8,257 & $5.1 \mathrm{TW} / \mathrm{hr}$ \\
\hline Total & ------ & $14.05 \mathrm{TW} / \mathrm{hr}$ \\
\hline
\end{tabular}

Rapid growth of the technologies and infrastructures should be updated frequently. The users also expect to handle more transactions in less time, to process and store more data and to automate more business processes; enterprises are installing more servers or expanding their capacity, all of which demand more computing power. This increase in computing power, devices and data center numbers. Analysts at Gartner recently suggested that by the end of $2008,50 \%$ of the data centers would not have enough power to meet the power and cooling requirements of the new equipment used in high-density server environments [3]

In the use of internet, social networking and search engines are contributing a major role. Even most of the users merely use social sites for entertainment only. This paper proposes the impact of environment through $\mathrm{CO} 2$ emission of social networks and search engines. The objective of green IT, energy saving and carbon reduction will be achieved.

\section{IMPACTS IN ENVIRONMENT}

The growing accumulation of greenhouse gases is changing the world's climate and weather patterns, creating droughts in some countries and floods in others. It's slowly pushing global temperatures higher, posing serious problems to the world. For instance, 2005 was the warmest year on record, and the 10 warmest years have all occurred since 1980 (www.nasa.gov/vision/earth/environment/2005_warmest.htm) 
because, the concentration $\mathrm{CO} 2$ in atmosphere is continuously increasing. The moderate $\mathrm{CO} 2$ level is $350 \mathrm{ppm}$ (parts per million) but in 2012 it over 390ppm. The high CO2 level outlets storms, droughts, cause respiratory disease, acid rain, climate change and other weather-related disasters are growing more severe and more frequent. To stop the accumulation of greenhouse gases in the atmosphere, global emissions would have to stop growing. Electricity is a major cause of climate change, because the coal or oil that helps generate electricity also release huge amount of carbon dioxide, pollutants, and sulfur into the atmosphere (table 2 [5]).

Table 2. Fual based $\mathrm{CO} 2$ emission

\begin{tabular}{|l|c|c|}
\hline Fuel type & \multicolumn{1}{c|}{$\begin{array}{c}\text { Percentage of global } \\
\text { primary energy supply }\end{array}$} & $\begin{array}{c}\text { Percentage of } \\
\text { global } \mathrm{CO}_{2} \text { emissions }\end{array}$ \\
\hline Oil & $34 \%$ & $38 \%$ \\
\hline Coal & $26 \%$ & $42 \%$ \\
\hline Natural gas & $21 \%$ & $20 \%$ \\
\hline Other* & $19 \%$ & $0 \%$ \\
\hline
\end{tabular}

(*Includes nuclear, hydro, geothermal, solar, tide, wind, combustible renewable, and waste)

The people must be aware of reducing electric power consumption which is a key to reducing carbon dioxide emissions and their impact on environment and global warming.

\section{ENVIRONMENTAL IMPACTS OF IT}

IT affects environment in several ways. Each stage of a computer's life, from its production, throughout its use, and into its disposal, presents environmental problems. All these stages are whether directly or indirectly increase carbon dioxide emissions and impact the environment (figure 1 [5]).

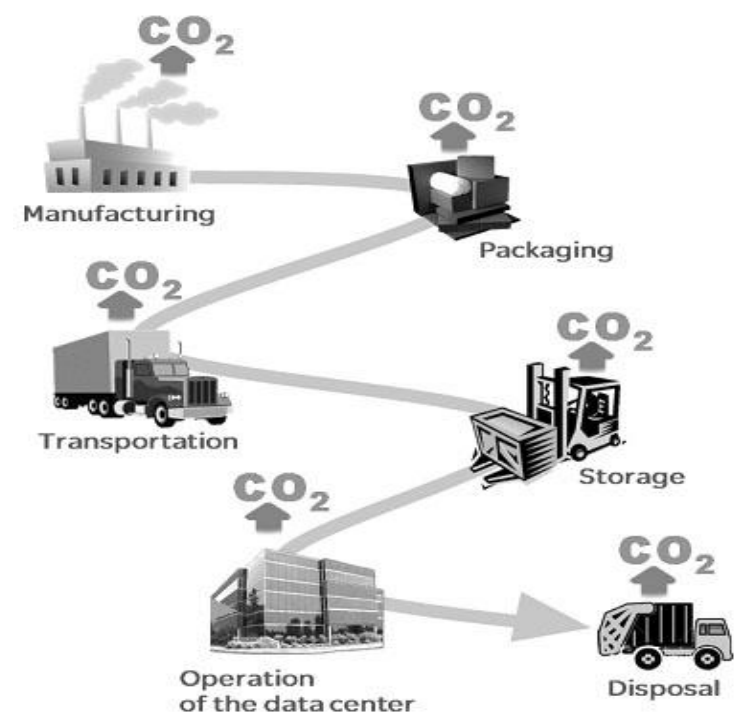

Fig 1: CO2 emission of computer's life

Every minute the total electrical energy consumption by servers, computers, monitors, data communications equipment, and cooling systems for data centers is steadily increasing.

Every single computer requires about 1.8 tonnes of chemicals, fossil fuels and water for its manufacture and once in use, it emits about 1.09 tonne of carbon dioxide in a year. A desktop PC system comprises of the CPU, a monitor, and printer. CPU may require approximately 200 watts of electric power. 40 watts for 17 inch LCD monitor. Laser printers can be required 100 watts.

It is widely assumed that a typical computer uses about 0.65 kilowatts per hour ( $\mathrm{kWh}$ ) in use, or $0.35 \mathrm{kWh}$ (stand-by) and $0.03 \mathrm{kWh}$ in hibernate mode. Assuming that the computer spends 220 working days with 12 hours in operational mode $(1716 \mathrm{~kW})$ and 12 hours in standby mode $(924 \mathrm{~kW})$, and spends 24 hours in hibernate mode for the remaining 145 days $(104 \mathrm{~kW})$, it will consume $2145 \mathrm{~kW}$ of electricity [6]. So the typical computer generates 1.09 tonne of $\mathrm{CO} 2$ per annum. According to UK government figures, $1 \mathrm{kWh}$ produces $0.51 \mathrm{~kg}$ of carbon dioxide (CO2), and 1,960kWh produces 1 tonne of $\mathrm{CO} 2$. This makes allowance for the fact that with current nuclear capacity (which is reducing) some $15 \%$ of electricity is generated without producing any $\mathrm{CO} 2$ [6]. The $\mathrm{CO} 2$ emissions by computers account for 2 per cent of world's total carbon dioxide emissions, almost equal to that contributed by aviation.

\subsection{Impact of Datacenters}

Data Centers are the Unsung Heroes of internet boom and data centers have been identified as one of the fastest growing consumers of energy. A data center is a factory that transforms and stores bits [7] and also it's a centralized repository, either physical or virtual, for the storage, management, and dissemination of data and information organized around a particular body of knowledge or pertaining to a particular business. The data centers are the responsible for all user based transactions and actions and reactions (figure 2). The modern datacenters have mainframe computers, servers, communication devices, data storage devices, routers etc.

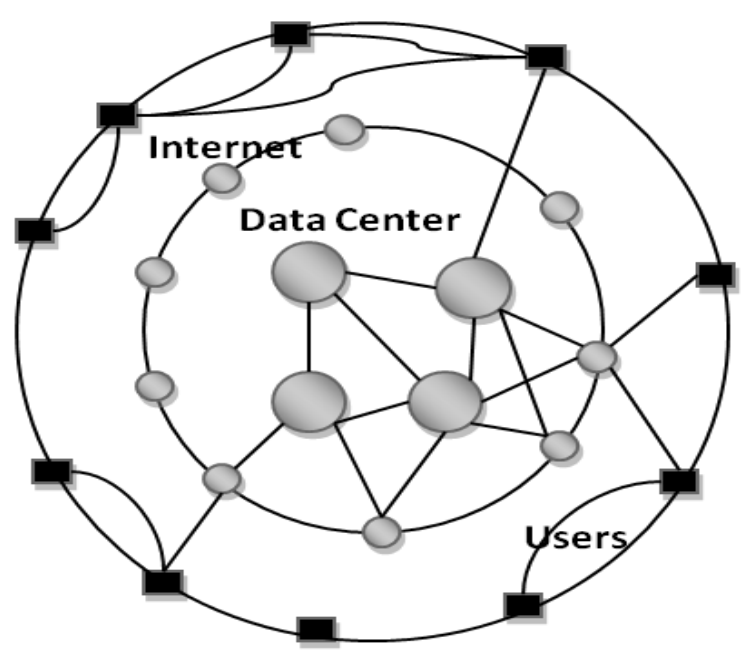

Fig 2: Working model of data centers. 
A typical 1980s server could be cooled quite easily, but though a modern server takes up much less floor space, it is more difficult to cool. Though it will require less power per unit of computing ability, but its overall energy requirement will be considerably higher, and the need for improved cooling will further increase energy requirements and environmental impact [6]. IBM estimate, the power demanded worldwide by data centers currently stands at 120 billion $\mathrm{kWh}$ a year [8].

A modern 10,000-square-foot data centre consumes more electricity than 8,000 60-watt light bulbs. That represents six to 10 times the power needed to operate a typical office building at peak demand, according to scientists at Lawrence Berkeley National Laboratory. Given that most data centers run $24 \times 7 \times 365$, the companies that own them could end up paying millions of dollars this year just to keep their computers turned on [9].

According to the report from US Environmental Protection Agency (EPA) (www.energystar.gov/ia/partners/ annualreports), data centers in US consumed about 60 billion $\mathrm{kWh}$ in 2006 , which was roughly 1.5 percent of the total US electricity consumption. It would be over 8 percent of the total US electricity consumption in 2020 [21]. Some data center statistics are

$>$ Data centers consume about 46 TeraWatt/hours in 2006 and it set to rise to $93 \mathrm{TW} / \mathrm{hr}$ by 2020 . In the US figure has been given as $70 \mathrm{TW} / \mathrm{hr}$ in 2007.

> 509,147 data centers worldwide, with 285.8 million square feet of space. There's enough data center space in the world to fit 5,955 football fields.

$>$ This year there will be 1.2 trillion gigabytes (GB) of data created, equivalent to 75 billion 16 GB iPods. That's more than enough for every person on earth to own 10 iPods.

$>$ A server purchased in 2011 has an average $45 x$ more compute capacity than a similarly configured server installed in 2001.

\subsection{Special Infrastructure of Data Centers}

Data centers are designed for computers, not people; most have no windows and minimum circulation of fresh air so its needs huge number of cooling equipments and special building infrastructure. In fact, data centers can be 40 times as energy intensive as an office building. Therefore, data centers more closely resemble industrial facilities than office buildings. Table 3 [5] reveals the requirements of the materials to construct typical data center (electricity and water requirements for construction and maintenance).

Table 3. Required materials for data center construction

\begin{tabular}{|c|c|}
\hline Material & Requirement \\
\hline Electricity & $177,000,000 \mathrm{~kW}-\mathrm{hr}$ \\
\hline Water & $227,000,000 \mathrm{ltr}$ \\
\hline Coper & $65,771 \mathrm{~kg}$ \\
\hline Lead & $9,525 \mathrm{~kg}$ \\
\hline Plastic & $14,968 \mathrm{~kg}$ \\
\hline Aluminum & $33,112 \mathrm{~kg}$ \\
\hline Solder & $5,443 \mathrm{~kg}$ \\
\hline Steel & $171,004 \mathrm{~kg}$ \\
\hline
\end{tabular}

Data center power consumption areas are mainly divided into IT load, Cooling system, UPS and power distribution and lighting and other overheads. Except IT load, the remaining areas are related to performance of the processing and infrastructure. IT load reflects how much power the IT equipment in the data center consumes. Loads can go up (an increase in processing requirements from the lines of business) or down (impact of virtualization or consolidation). The higher the load, the more power will be required to keep it up and running and the higher the carbon footprint. If the data center have minimum IT loads the total operating electricity is notably down.



Fig 3: Data center power consumption

\section{ENVIRONMENTAL IMPACT OF SOCIAL NETWORKS}

The frequent use of social networks and search engines is driving the rapid growth of data centers and an increase in energy use. Today majority of people consider as prestigious issue of using social networks. If a student or youngster is not be a facebook user, the neighbours will be kidding them. Today 18-34 year olds are most active social networkers, they are merely $73 \%$ of total users of facebook [11]. In 2012, there are 2.4 billion Social networking (facebook, twitter, linkedin etc) accounts in worldwide. Among social networking service facebook plays major role. Facebook has more than 800 million users ( 1 in every 13 people on earth) and 500 million users are active every day and its reveals they are pressure to data centers and consume network equipments and making internet traffic. Even that $23 \%$ of facebook's users check their account about 5 or more times daily.

Due to this numbers, facebook data centers and operations (include network equipments, PC) use 532 million $\mathrm{kw} / \mathrm{hr}$ of energy, and emitted 285,000 metric tonnes of $\mathrm{CO} 2$ equivalent off-course the facebook estimates that each user of the service produces an average of 269 grams of carbon per month. The worldwide facebook access except for China and Russia facebook is no 1 in 126 out of the 137 countries that were analyzed. Europe is the largest contingent on facebook with 232 million users, while North America has 222 million and the whole of Asia boasts 219 million users. 
When using a video portal, did you ever imagine how much amount of energy is used? Just when the users are watching your favorite video on Youtube, 1 minute of streaming requires $0.0002 \mathrm{kWh}$, and generates approximately $0.1 \mathrm{~g}$ carbon dioxide [www.google.co.in/green/bigpicture/], doesn't look much? But put this into the calculations: 1 trillion of video playbacks on YouTube server it equal to 140 of YouTube video playbacks per person on Earth and everyday around 2 Billion videos are viewed on Youtube. So around the world most of the people generate $\mathrm{CO} 2$ through their entertainment.

\section{ENVIRONMENTAL IMPACT OF SEARCH ENGINES}

There is a discussion between software engineer, one said "internet saves green and save environment" another says "internet minimize transportation and letter transactions" yes it true, but one thing to reveal that internet and search engines are also polluting environment significantly. The 2,267,233,742 people accessing internet and produce a huge no of $\mathrm{CO} 2$. For example Google now represents an average $6.4 \%$ of all Internet traffic around the world and it generated a total of 1.68 million metric tons of carbon dioxide, if it will include data center footprint, it would have been about twice as big.

As Google report the year 2011 electricity consumption was 2,675,898 MWh. Today the search engines are seventh sense of most of the developers but the search engines are also emit significant CO2. Every Google search requires 0.0003 $\mathrm{kWh}$ of energy to answer the average search query; this translates into roughly $0.2 \mathrm{~g}$ of carbon dioxide [12]. Google products provide over 3 billion searches every day (mere 600 tonnes of $\mathrm{CO} 2$ ), and it busy with mobile mapping for over 200 million smart phone users, and host over 5 million businesses in the cloud. Even Google uses $2.1 \mathrm{kWh}$ per Gmail user every year, and generates $1.2 \mathrm{~kg}$ of carbon dioxide [12].

\section{MIGRATION TO GREEN IT}

Renewable energy is not a better solution to reduce $\mathrm{CO} 2$ emission and its does not compensate technology and users growth of IT. Every IT user, developer and manufacturers should involve analyzing and designing a new version of computing infrastructure. Green IT is the only solution to reduce $\mathrm{CO} 2$ emission through $\mathrm{IT}$.

Green IT (Green Information Technology) refers to environmentally sound IT. It's the study and practice of designing, manufacturing, using, and disposing of computing devices. Green IT aims to reduce the environmental impact of computers by adopting new technologies and using new techniques and materials while balancing environmental compatibility with economic viability and performance [13]. To create Green IT awareness the investors and consumers are beginning to demand more disclosures from companies with regard to their carbon footprint as well as their environmental initiatives and achievements.
The researchers and designers are focusing on converting the existing technologies into greener. Those migrating technologies that are given below

- Green Mining

- Green Cloud

- Green Cellular Network

- Green Database

- Green Internet

- Green Operating System

- Green Pervasive Computing and etc.

These all green technologies are imposing the power efficiency of computing and environmental friendly. It explores some research issues and challenges and suggests some techniques to enable energy efficient.

\section{ARCHITECTURE OF GREEN IT}

This paper early stated, “Each stage of a computer's life, from its production, throughout its use, and into its disposal, presents environmental problems" so green IT focus to reduce $\mathrm{CO} 2$ emission in all stages. Green IT approach that addresses the problems along the following four complementary paths

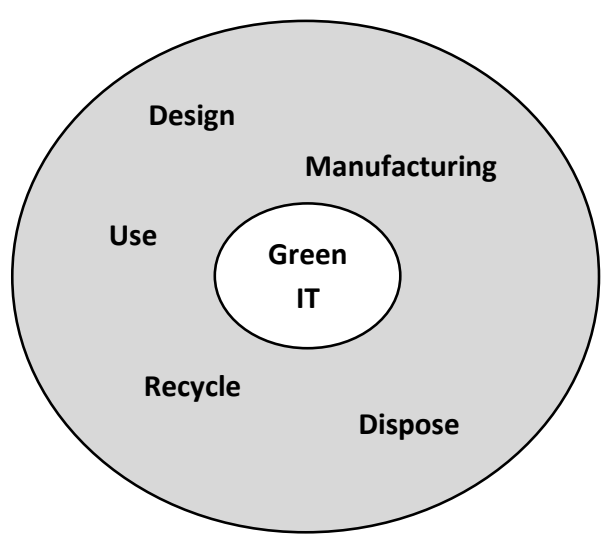

Fig 4: Architecture of Green IT

$>$ Green design: Design energy efficient and environmentally sound components, computers, datacenters, and cooling equipments.

> Green manufacturing: Manufacture electronic components, computers, and other associated subsystems with minimal or no impact on the environment.

$>$ Green use: Reduce the energy consumption of computers and other information systems and use them in an environmentally sound manner

$>$ Green recycle: Refurbish and reuse old computers and properly recycle unwanted computers and other electronic equipment.

> Green disposal: Management of e-waste and safe disposal of computer components without environmental impacts

\subsection{Designing of Green Computers}

The main objective of the Green Design and Manufacture is make computers and devices are energy efficient and focusing green disposal and reuse. For example the move from singlecore to dual- and quad-core processors saves power while 
increasing processing performance. This contrasts the old method of improving performance of microprocessors by increasing the frequency of the chip's operation, which hugely increases power consumption and heat generation. A 15 percent reduction in frequency could save up to 50-percent power consumption [13].

\subsection{Greening a Data Centers:}

Use cloud computing to reduce data centers. According to market research, the wide-spread adoption of cloud computing could lead to a potential $38 \%$ reduction in worldwide data center energy expenditures by 2020 [14].

\subsection{Green Use}

\section{Reducing energy consumption by PCs:}

Users can significantly reduce energy consumption by making small changes to the ways they use computers. Most personal desktop computers run even when they aren't being used, because users needlessly leave them on, wasting electricity. Furthermore, computers generate heat and require additional cooling, which adds to the total power consumption and cost for the enterprise.

$>$ Review document drafts and e-mails onscreen instead of printing them out

$>$ Consider using an ink-jet printer although a bit slower than laser printers, inkjets use 80 to 90 percent less energy.

$>$ Choose dark backgrounds for your screen displaybright-colored displays consume more power.

\section{Enabling power management features:}

Without sacrificing performance, developers can program computers to automatically power down to an energy-saving state when users aren't using them. Providing computers with a sleep mode reduces their energy use by 60 70 percent [13].

\subsection{Green Recycle}

The users should refurbish and reuse or recycle electronics components in environmentally sound ways and can reuse most of the components to manufacturing. For example the old CPU cabinets will refurbish and redesign to modern computers. Most of the electronic components in the motherboard can be reused in the new products. Even the users can use old computers for billing or functional process.

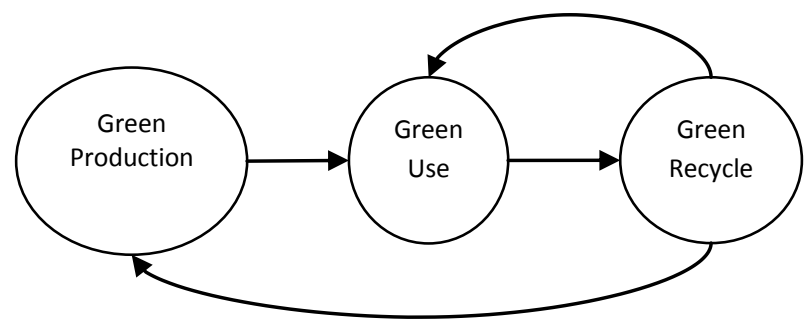

Fig 5: Process of Green Recycle

\subsection{Green Disposal}

Unwanted computers and monitors shouldn't be thrown away in rubbish bins, as they will then end up in landfills causing serious environmental problems. Instead, it uses biological compositing, produce power from e-waste incineration etc.

\section{ANOTHER PERSPECTIVE OF GREEN} IT

Besides IT itself being green, it can support, assist, and leverage other environmental initiatives by offering innovative modeling, simulation, and decision support tools, such as [13]

$\checkmark$ Software tools for analyzing, modeling, and simulating environmental impacts.

$\checkmark \quad$ Urban environment planning tools and systems

$\checkmark \quad$ Integrating and optimizing existing environmental monitoring networks and new easy plug-in sensors.

$\checkmark$ Tools for auditing and reporting energy consumption and savings and for monitoring greenhouse gas emissions

\section{CONCLUSION}

In this paper, identify the problem of excessive energy consumption of internet, social networks and search engines and propose a generic approach to save energy. Production of renewable energy is not a better solution to IT's impact, but the users should reduce their un-necessary usage of internet and social sites and feel the responsibly to the environment. The rising of internet users should also have awareness of carbon footprint and environmental impacts. People have begun to value the attributes of environmental friendly of IT and the companies will offer a range of new green products and services, and new business opportunities will emerge. Energy saving is better than production.

\section{REFERENCES}

[1] "How dirty is your data?", Greenpeace International, 2010.

[2] Maruti Gupta and Suresh Singh, "Greening of the Internet", SIGCOMM, 2003.

[3] Richard Fichera, "Power And Cooling Heat Up The Data Center”, Forrester Research, March 2006.

[4] http://www.nasa.gov/vision/earth/environment/2005 _warmest.html

[5] Dennis Bouley, "Estimating a Data Center's Electrical Carbon Footprint" Schneider Electric's data center science center, 2011

[6] "Green IT - the next burning issue for business", IBM Global Technology Services, January 2007.

[7] Albert Greenberg, David A. Maltz, "What Goes Into a Data Center?", Microsoft research, 2009.

[8] "Bringing energy efficiency to your data centers IBM Energy Efficiency Initiative”, IBM Global Technology Services, March 2007

[9] Susannah Patton, "DATA CENTERS Powering Down", CIO.com, April 2006.

[10] EPA 2011 Report to Congress, http://www.energystar.gov/ia/partners/annualreports 
[11] "State of the Media: The Social Media Report", Nielson, 2011

[12] http://www.google.co.in/green/bigpicture/

[13] San Murugesan, "Harnessing Green IT - Principles and Practice”, IEEE computer society, 2008.

[14] Abram Hindle, "Green Mining: Investigating Power Consumption Across Versions", International Conference on Software Engineering (ICSE), 2012.

[15] "Measurement of data centre power consumption", Cisco, 2010

[16] K. L. Giridas, Shajin Nargunam, Optimal Resource Allocation Technique (ORAT) for Green Cloud Computing, International Journal of Computer Applications, 2012.

[17] "The Social Habit” Edison Research, 2012

[18] Edward Curry, Souleiman Hasan, Mark White, Hugh Melvin, "An Environmental Chargeback for Data Center and Cloud Computing Consumers", Computing and Communication Meet (e-Energy 2012), 2012

[19] Saurabh Kumar Garg and Rajkumar Buyya, "Green Cloud computing and Environmental Sustainability",
Cloud computing and Distributed Systems (CLOUDS) Laboratory press, 2010.

[20] Ziaul Hasan, "Green Cellular Networks: A Survey, Some Research Issues and Challenges", arxiv, 2011.

[21] William Forrest, James M. Kaplan, and Noah Kindler, "Data centers: How to cut carbon emissions and costs", McKinsey on Business Technology, 2008.

[22] http://www.emersonnetworkpower.com/enUS/Abou t/NewsRoom/Pages/2011DataCenterState.aspx

[23] http://searchdatacenter.techtarget.com/definition/datacenter

[24] http://www.bdrc-continental.com/social-media/

[25] http://archive.unu.edu/update/archive/issue31_5.htm

[26] http://royal.pingdom.com/2012/01/17/internet-2011-innumbers/

[27] http://www.guardian.co.uk/environment/2010/aug/12/ carbon-footprint-internet 